\title{
An evolution of the methods for and purposes of mine closure cost estimating
}

\author{
J.V. Parshley SRK Consulting, United States of America \\ W. Bauman Barrick Gold Corp., United States of America \\ D. Blaxland Barrick Gold of Australia Limited, Australia
}

\begin{abstract}
The last two decades have seen a significant evolution in both the methods for and purposes of closure cost estimating. As part of this evolution, changes in the uses of closure cost estimates have resulted in coincident changes in the scope, methods employed and level of detail required.

Prior to the development of regulatory requirements to prepare closure cost estimates, closure cost estimates were typically intended for planning, design and contracting of the actual closure, and were often developed late in the mine life cycle. The level of detail required was largely determined by the number of years remaining in the operational life of the mine at that time. The nearer to the time of closure, the more detailed the closure design and cost estimate became. These closure designs became the basis for construction contract bidding and tracking purposes.

As mining laws changed and the need to provide financial surety for closure activities became a priority, the focus of closure cost estimating in many countries was to reduce the liability of the government that would assume responsibility should the operator abandon the site prior to planned closure.

The latest evolution of closure cost estimating techniques has been focussed on improving closure cost estimating for the purpose of accurate reporting of financial liabilities to shareholders, lending institutions and governments. Requirements for reporting mine closure liabilities have added a new dimension to the scope and detail of closure cost estimating.

This paper documents the history of mine closure cost estimating since the 1970s and discusses the influence that different purposes for mine closure cost estimates have had on the evolution of methods used to develop those estimates. Several examples of successes and failures in closure cost estimates for actual mine sites and the regulatory programmes that oversee the closure of these mine sites are presented as illustrations of the progression of closure cost estimating and demonstrate the importance of this discipline in the mining life cycle process. Current trends in the current best practice and their probable impact on the future of closure cost estimating are also discussed.
\end{abstract}

\section{Introduction}

Prior to the existence of the first legal requirements to estimate a closure cost and provide financial assurance came into effect in the US in the mid 1970s, the primary use of closure cost estimates by the mining industry was to plan, budget and manage actual closure activities. However, since the modern environmental laws were limited at that time, most mining operations during the 1970s had no plans or obligations to perform any closure activities whatsoever. Instead, the focus was generally on decommissioning and salvage of valuable equipment and materials, or mothballing operations for possible future re-use.

With the promulgation of US Forest Service (USFS) hard rock minerals regulations in 1974 (36 CFR 228), the Office Surface Mining's Surface Mining Control and Reclamation Act (SMCRA) of 1977 for coal mines and the US Bureau of Land Management (BLM) hard rock minerals management rules in 1980 (43 CFR 3809), the focus of closure cost estimating switched to providing the government agencies and the public assurance that sufficient funds would be available in the event that the mining company did not meet its now defined closure obligations. During the subsequent 25 years, other countries passed similar laws and regulations requiring mining companies to plan and provide financial assurance for responsible closure of 
their operations. The primary intent of mine closure cost estimating, in most jurisdictions, was to estimate the cost that the government would incur should a mining company default on their commitments to close their operation in accordance with an approved closure plan. As the industry and government regulators gained experience in this field, the scope and level of detail of these financial assurance closure cost estimates has concomitantly increased as well.

However, until the late 1990s, when severely depressed metal prices forced a number of companies into insolvency, the effectiveness of the rules, guidelines and methods used for closure cost estimating had not been fully tested. The failure of several companies around the turn of the millennium brought to light a number of deficiencies in the financial assurance systems in place in several jurisdictions. This resulted in an urgent and frank appraisal of many of these systems by government, industry and the public. Many jurisdictions implemented new controls and cost estimating methods as a result. New standards such as the standardised reclamation cost estimator (SRCE) developed in the State of Nevada were developed and implemented. The result of this was that the magnitude of many financial assurance cost estimates increased dramatically.

The most recent development in closure cost estimating is the new emphasis on compliance with financial reporting requirements, including the US generally accepted accounting principles (GAAP) and the International Financial Reporting Standards (IFRS). With the well publicised failure of several large US corporations, such as Enron and Tyco, resulting from questionable and illegal accounting practices, most mining companies began to re-evaluate their systems for compliance with the financial reporting requirements of closure liabilities. The awareness of the potential consequences for misreporting of corporate liabilities caused many mining companies to implement new controls and systems to ensure that closure liabilities were properly defined, quantified and reported.

This changing emphasis has resulted in a significant evolution in the standards and methods used for determining the financial liability associated with closing mining and mineral processing operations. Part of this evolution has been to develop methods that simplify the development of three separate closure cost estimates for three common, but different purposes: planning and budgeting; financial assurance; and financial reporting.

\section{Types of closure cost estimates}

There are three basic types of cost estimates, each of which has a varied purpose and specific requirements regarding the basis of the estimate. It is important recognise the difference between these types and clearly specify which type of estimate is being used rather than using generic terms like 'mine closure cost estimate' or 'closure cost estimate' without an appropriate qualifier. The three types of closure cost estimates commonly used by the international mining industry today and their specific requirements are:

\subsection{Financial assurance cost estimate (FACE)}

This type of estimate defines costs that the jurisdictional government agency would incur to perform all of the actions required to fulfil an approved closure plan should the company abandon the site without implementing closure. FACEs are usually used to determine the amount of financial assurance required under governing laws and regulations, and social commitments.

- Many jurisdictions require that FACEs assume that a third-party, i.e. independent contractor, performs the closure work prescribed in the approved plan. This is generally because most governments does not have the internal resources to complete the work and will be required to secure the services of an outside contractor to perform the work.

- Some jurisdictions also define the methods used to prepare the cost estimate. For example, in South Africa, the Department of Minerals and Energy has developed guidelines for calculating the quantum of financial assurance and provides an electronic form for calculating the closure cost. In the US, regulators and the mining industry worked cooperatively in the State of Nevada to develop a more sophisticated model for the estimating of closure costs for financial assurance. 
- Because government agencies will incur additional overhead and management costs when contracting with private entities, FACEs may also include specific indirect costs that the government adds to the estimate in order to cover those anticipated expenses.

- In some jurisdictions, closure contracts are also subject to government contracting laws. These may require the use of government mandated labour rates, additional manpower requirements, and/or fixed profit margins.

- FACEs typically cover the current or maximum near-term closure cost of the operation. Many jurisdictions have mandated terms for permits and closure cost estimates, and require periodic updates. Usually, a FACE will determine the maximum liability that will exist during the term of the estimate, and use that as a basis for the cost estimate and financial assurance.

- FACEs may not include some costs that would be incurred by a mining company during closure, but not by the government. Examples of this would include taxes, the cost of maintaining a financial assurance instrument and employee severance.

- Reduction of any portion of the financial assurance amount is usually only allowed after the government agency, with legal jurisdiction, has officially determined that the work (or a portion thereof) has been performed in accordance with applicable laws, regulations and permit conditions.

- Normally, FACEs are estimated on a current cash basis. In other words, the cost that would be incurred if the work were performed at the time the estimate is prepared.

- Salvage value of equipment and scrap are not normally included in FACEs, but some jurisdictions do allow the cost estimate to account for salvage, residual production, or equipment resale.

- The types of financial assurance instruments vary based on jurisdiction, but often require some type of third-party guarantee instrument for which the mining company will typically pay 0.37 to $1.5 \%$ of the face value annually (Miller, 2005).

\subsection{Life of mine (LOM) closure cost estimate}

This is the estimated cost for the mine operator to perform all of the actions required to fulfil the closure portion of their current mine plan in the context of operations. LOM estimates are usually used for planning, budgeting and cost tracking. Common uses for LOM closure cost estimates include prefeasibility and feasibility studies, due diligence audits, accrual allocation, annual planning and budgeting, and cost tracking.

- Unlike a FACE, a LOM closure cost estimate normally includes all planned development currently included in the mine plan, regardless of when it is or will be constructed.

- Because a LOM cost assumes that the mine operator will use their own equipment and labour for the closure work, mine operator costs are usually assumed. The exception to this would be speciality work such as dismantling of buildings and/or equipment, or hazardous waste removal that would normally be contracted to a third party.

- As work is completed at the site, the cost estimate would be revised to reflect the reduction in liability as soon as the work is complete or when the estimate is next updated. Approval of the jurisdictional authorities is generally not required.

- Because LOM costs are used in long-term planning and budgeting, they are usually calculated on a cash flow basis. Scheduling of closure costs in accordance with the mine plan and closure plan allows the LOM cost to be incorporated into the operational cost model.

- Residual production value, and revenue from the resale or salvage of equipment and scrap, may be included in the cost estimate. However, many companies choose to omit these until late in the mine life cycle when potential revenue from residual production and salvage and resale markets are better defined. 


\subsection{Asset retirement obligation (ARO) cost estimate}

This is a legally defined term used for financial reporting by US and a number of other IFRS-compliant international stock markets. This term, and its legal requirements, is defined in the Financial Accounting Standards Board (FASB) Statement 143 (FAS 143) and the London based International Accounting Standards Board (IASB) Standard 37 (IAS 37). ARO cost estimates must be prepared each year as part of the annual financial reporting requirement and adjusted to reflect any increases due to new development work or reductions resulting from completed closure work that occurred in the financial reporting year.

An ARO estimate is the fair value of abandonment liabilities associated with mining and mineral processing operations for financial reporting. In other words, it is the amount a mining company would pay a third party to assume responsibility for completing all closure activities, including a reasonable profit margin.

An ARO is typically approved by the company's executive management, e.g. chief financial officer and/or chief executive officer, at a minimum, but many companies are requiring a lengthy signoff process starting with the site environmental manager. Negligent or intentional misreporting or underreporting of an ARO can lead to criminal penalties for the signatories. Given the recent concerns about public disclosure and financial reporting to stockholders, the requirements of these ARO cost estimates are rapidly becoming the primary focus of closure cost estimates for many companies.

- AROs include all legal requirements for closure. This means that any obligation defined by law, permit, landowner agreement, contract, or other verbal or written commitment made by the company. This includes any type of commitment considered a legal obligation, including obligations created under the doctrine of promissory estoppel in the US and defined as a Constructive Obligation in IAS 37. This type of obligation:

"derives from an entity's action where a) by an established pattern of past practice, published policies or a sufficiently specific current statement, the entity has indicated to other parties that it will accept particular responsibilities; and b) as a result, the entity has created a valid expectation in those parties that they can reasonably rely on it to discharge those responsibilities." (IASB, 2004).

In other words, if a company has made commitments in a public forum, consistently made similar commitments or included those commitments in publicly available corporate policies, those commitments are considered 'legal' under the definition of an ARO and must be included in the ARO closure cost estimate.

- AROs include only those liabilities, development, commitments, etc., existing by the end of financial reporting year. Normally, if a facility exists at the end of the fiscal year, the cost for closing that facility is included. However, the scope of work required may be significantly less if the facility was constructed during a reporting year, but not yet commissioned.

- AROs do not include any activities that a third-party would not incur in meeting the legal obligations, regardless of whether it is included in the current mine plan, e.g. severance payments to the closure staff, home office overhead, taxes, etc.

- Reduction of any portion of the cost estimate may be allowed as soon as the work is complete, e.g. demolition work, or may require that the government agency with legal jurisdiction has officially determined that the work has been performed in accordance with laws, regulations and permit conditions, e.g. vegetation monitoring has demonstrated the vegetation is self-sustaining.

- Like a LOM cost estimate, AROs are calculated on a cash flow basis for inclusion in the corporate financial model.

- In accordance with FASB and IASB standards, revenue from residual production, or the resale or salvage of equipment and scrap cannot be included in the cost estimate.

Although it may seem that the differences between these types of closure cost estimates are subtle, the final product, quantum and intended use may not be. Furthermore, because most companies will require each type of cost estimate, it is important that they not be confused or the implications could be serious. If a company is trying to prepare documentation to list their company on a stock exchange, they will need an ARO closure 
cost estimate for the initial public offering (IPO). However, they may also require a LOM closure cost estimate for any project feasibility studies that are part of the corporate documents required for listing. When a project finally gets funded and permitted, a surety closure cost estimate may be required. Therefore, it is important to understand the differences in these types of closure cost estimates and use the appropriate type in each circumstance.

Table 1 Types of closure cost estimates

\begin{tabular}{llll}
\hline & FACE & LOM & ARO \\
\hline Use(s) & Financial assurance & $\begin{array}{l}\text { Planning (prefeasibility, } \\
\text { feasibility), budgeting, etc. }\end{array}$ & $\begin{array}{l}\text { Financial reporting to } \\
\text { shareholders, IPOs }\end{array}$ \\
$\begin{array}{l}\text { Rate basis } \\
\begin{array}{l}\text { Included } \\
\text { development }\end{array}\end{array}$ & Third-party & $\begin{array}{l}\text { Operator and third-party } \\
\text { All development contained }\end{array}$ & $\begin{array}{l}\text { Operator and third-party } \\
\text { in current mine plan } \\
\text { at the end of the current } \\
\text { financial year }\end{array}$ \\
$\begin{array}{l}\text { Govt. contracting } \\
\text { rules }\end{array}$ & In some jurisdictions & No & No \\
$\begin{array}{l}\text { Cost basis } \\
\begin{array}{l}\text { Salvage value } \\
\text { allowed }\end{array}\end{array}$ & Current cash & Cash flow & Cash flow \\
\hline
\end{tabular}

\section{Nevada, 2001 - the first real test of financial assurance cost estimate requirements}

The first real test of the financial assurance requirements implemented in several countries occurred in the State of Nevada in the US at the turn of the millennium when the requirements were nearly 20 years old. By the late 1990s, the mining industry had closed a number of modern mine sites using the techniques commonly included in BLM and Nevada State closure plans of that era. However, Nevada Division of Environmental Protection (NDEP) and the federal land management agencies such as the BLM and the USFS had closed and reclaimed only a few, small sites using funds from financial assurance instruments.

At the turn of the millennium, low metal prices forced several small to mid-size mining companies into insolvency, leading to the ultimate abandonment of their operations. In Nevada, approximately 20 mine sites were abandoned and left to the state and federal regulators to manage into close. These bankruptcies tested the scope and efficacy of the federal and state financial assurance programmes that were supposed to provide regulators (and the public) with sufficient financial resources to reclaim abandoned or bankrupt mines. However, as the NDEP and the federal agencies began to implement closure plans, and use the allocated financial assurance funds at these bankrupt sites, programme-wide deficiencies and inefficiencies became readily apparent.

Audits of most of these sites determined that the financial assurance supplied by the mining companies were grossly inadequate in nearly every case. The financial assurance funds available to the government at these sites varied from zero to fifty percent of the planned closure, and the planned closure in many instances would not provide for acceptable post-closure conditions. At the Griffon Mine, for example, the available financial assurance was approximately US $\$ 771,000$ based on the cost estimate submitted by the mining company. However, the final amount spent by the USFS to close the site was nearly US\$ $1.5 \mathrm{M}$.

At the Arimetco Yerington site, the company had posted a corporate guarantee as the form of financial assurance, but since the company was bankrupt, the real value of that guarantee was zero. Because of the immediate need for management of process solutions on this site, the NDEP immediately assumed control and hired a third-party contractor to manage process fluids and prevent any environmental releases. Over the next six years, the NDEP spent nearly US\$ $2.5 \mathrm{M}$ managing water at the site. To this day, the majority of the site has yet to be closed. 
The Nevada mining industry, the NDEP, and federal regulators readily agreed that this situation was unacceptable, and that changes in the financial assurance requirements were desperately needed. Working cooperatively over the next few years, the industry and state and federal regulators identified the specific deficiencies that were encountered at the abandoned operations, and found acceptable solutions to address each one to ensure that adequate funding would be immediately available to state and federal agencies should any additional bankruptcies occur in the future.

This cooperative effort between the mining industry and regulatory agencies in Nevada has resulted in a programme that is embraced as being fair, defensible, and reasonably accurate. All parties recognise that this programme may result in somewhat conservative cost estimates. However, the shared commitment to capitalise upon the lessons learned from responding to unexpected situations at the bankrupt sites, and to modify the bonding programme to eliminate the shortfalls that were due to these unexpected situations, makes a conservative approach essential. The resulting revisions to the financial assurance programme in Nevada, and newly developed tools, provide comprehensive cost estimates that consider likely contingencies. The Nevada financial assurance programme is now considered to be one of the most complete and effective in the US (Parshley and Struhsacker, 2009).

Similar industry-agency collaboration recently occurred in the State of Montana, where the Montana Mining Association and the Montana Department of Environmental Quality worked together to update Montana's financial requirements. This cooperative effort resulted in a new law to amend the Montana Metal Mine Reclamation statute to provide for temporary bonding in unanticipated circumstances.

Other countries and government jurisdictions have been watching the developments in the US with an eye to their own laws and regulations to ensure that the challenges experienced in Nevada are not repeated elsewhere. In many South America countries, where mining is a major economic activity, the fluctuation in metal prices has caused a number of mining companies to declare bankruptcy over the last three decades, leaving behind social and environmental liabilities with which the local, regional, and national government agencies must deal.

For example, in Peru, the authorities are facing many environmental liabilities from mining activities at more than 100 sites and many of the environmental liabilities are quite extensive. This situation forced the authorities to implement mine closure regulations and financial assurance requirements for mining activities beginning in 2003. The regulators found that the process of developing mine closure regulations was far more complex than expected due to the wide range in the scale of mining operations in the country, from family owned and artisanal mines to large international mining company sites. As a result, Peruvian mine closure regulations distinguish between artisanal and small scale operations, and larger scale operations, scaling the requirements for the closure activities and financial assurance appropriately to the size of the operation. In parallel to the US, the Peruvian authorities worked with the Peruvian mining industry and other governments to develop mine closure and cost estimating guidelines to assist operators, especially the artisanal and small-scale miners, in complying with the new regulations.

In 2005, the New South Wales (NSW) Department of Primary Industries (DPI) - Mineral Resources released a closure security deposits policy (NWS-DPI, 2005) with the primary aim that the people of NSW do not incur a financial liability as a result of mining and petroleum activities. The operator is required to submit a security deposit to cover the Government's full costs in undertaking reclamation in the event of a potential default. The policy aims to encourage progressive reclamation through regular review of liabilities and progressive release of security deposits where appropriate. The key change to this policy from earlier versions is the requirement to provide the State with an estimate of reclamation costs. The State is required to consider this when determining the amount of security deposit calculation. The policy was supported by a guideline (NSW-DPI, 2006) which sets out the security process, forms of security deposit, cost estimate requirements, basis of calculation, cost methodology and release of security. As part of the guideline, the DPI has prepared a cost calculation tool to assist in cost estimates; however, the DPI will accept alternative cost estimate methodologies subject to DPI approval. Alternative methodologies must be based on third-party rates and include schedule of closure work, cost breakdown by activity and schedule of costs. In 2008, Barrick received approval from the DPI to use the SRCE as a basis for the calculation of the security deposit calculation for the Cowal Gold Mine. 
In all cases, the need for adequate financial assurance should be balanced with the need to allow mining companies to utilise their financial resources for operations and maintaining their operational environmental programmes. Otherwise, because many companies are required to provide hard cash financial assurance instruments, forcing over-inflated closure cost estimates on the industry which could deplete corporate cash reserves and precipitate the very circumstances that would cause a default.

\subsection{Lessons learned from the Nevada bankruptcies}

During the review of the Nevada financial assurance programme, a number of deficiencies were identified in the methods and approaches used for estimating the closure costs, as well as the types of and process for approving types of financial assurance instruments. The following are the major issues acknowledged during the review and revamping of the mine closure and financial assurance requirements, and which are potentially applicable to other jurisdictions and types of mine closure cost estimates.

\subsubsection{There is no substitute for a proper closure plan}

Without a proper closure plan it is difficult to accurately determine the cost that will be incurred to close most mining operations. This was the case with nearly all of the bankrupt sites in Nevada. Because the closure plans were not well defined, a number of activities required to close the sites were poorly understood and others overlooked altogether. As a result, costs for these activities were underestimated or left out of the financial assurance cost estimate, leaving the government exposed, and with insufficient funds to properly close the mines. For example, at the Elder Creek gold mine, there were no provisions to close the solid waste landfill or the underground sewage system. At the Gold Bar Mine, the closure plan did not include activities or costs required to close the material borrow areas used as a source of cover material for the tailings impoundment or the water supply wells.

Although many operations had provided detailed closure plans since the NDEP regulations were promulgated in 1990, the level of detail of some plans clearly did not provide an adequate basis for estimating closure costs. Subsequent to the bankruptcies of 2000, the government agencies met with industry representatives to produce a new cost estimating model which, among other benefits, provided a logical approach to assessing the totality of closure activities. This model is now used by most mining operations in Nevada, and continues to evolve as mining companies and the government gain additional experience with mine closure.

While recognising that the level of detail that can be realistically provided in a closure plan will vary, depending on when in the mine life cycle the plan is being prepared, the closure plan should still consider all of the facilities that will need to be closed and activities required to close those facilities. As a project matures, experience from operations and contemporaneous closure activities should allow subsequent updates of the closure plan to become more detailed and provide a greater confidence in the closure cost estimate.

\subsubsection{Cost estimate methods based on average costs per area only work on average projects}

The bankrupt mines had calculated portions of their cost estimates based on typical costs-per-area. These cost-per-area unit rates are generally based on an average costs expected or measured at a number of mine sites. Unfortunately, a number of factors may cause these average unit rates to be completely inappropriate for many sites. These factors include:

- The remoteness of the site.

- The configuration of facilities such as waste rock dumps and tailings impoundments.

- Materials available for barrier and revegetation covers.

- The size of the site and distances between project facilities and reclamation material stockpiles.

- The availability of labour and equipment for closure work.

Although most Nevada mine operators had used first principle approaches, site data and/or contractor quotes to prepare closure cost estimates since in the early 1990s some of the bankrupt sites had used rough estimates 
to provide an average cost per area for different activities. However, site-specific (not average) conditions at some of these sites caused this approach to seriously underestimate the actual closure costs. Since that time, the NDEP and BLM will only accept cost estimates based on first principles, published databases, verified site data and/or certified construction contractor quotes for the preparation of financial assurance cost estimates.

\subsubsection{Inadequate short-term funds available to manage sites prior to closure period}

Because the government and industry experience with mine closure at that time was based on planned and orderly closure performed by the mine owner, some costs associated with government management and the timing of mine closure had not been anticipated. For example, some sites required immediate management of process solutions to ensure that the environment was protected against the inadvertent release of process solutions, but the procedure of obtaining the money from the bonds often took several months, during which time bond funds to manage the site were not available. Other emergency funding programmes had to be used to cover this deficiency at that time.

As part of the programme revisions, a fund was set up to ensure that money would be immediately available for site management at any site declaring bankruptcy. Now, all financial assurance cost estimates in the state of Nevada must include the cost for managing the site, including all process fluids, for a period of six months under typical care and maintenance conditions.

Process fluid management costs during the closure period should be included in any type of closure cost estimate. The requirement and amount of these expenditures is often overlooked in the closure cost estimate if there is not a clear delineation between the point in the life cycle where operations cease and closure begins. Often, closure is assumed to begin when the last ore is sent for processing, but it may also be defined as the time when active processing ceases. In the case of heap leach pads, it might be defined as the point in time when gold can no longer be economically recovered. Defining this point clearly in a closure plan, and ensuring that there are no gaps in the accounting of expenditures between operations and closure, should help avoid shortfalls in the closure cost estimate. Although applicable to all types of closure cost estimates, these types of costs can be significant in the case of unplanned or early closures, even if the mining company performs the closure work internally.

\subsubsection{Hourly equipment rates should reflect the entity doing the work}

One of the reasons that the financial assurance estimates for the bankrupt sites were inadequate was because some of the hourly equipment and labour rates used in the estimates did not reflect the agencies' costs to contract the work to third parties. The equipment rates used to determine the financial assurance amounts were based on a number of sources including mine operator costs and varied widely from site to site.

A small working group comprised of Nevada mining industry professionals and regulators investigated a number of options to provide realistic hourly equipment rates, and ultimately decided that the local equipment suppliers' monthly, single-shift rental rates were most appropriate - even though it is highly unlikely that a contractor would only work their equipment for 40 hours per week on this type of job. This is one of the acknowledged areas where the cost estimates are conservative, because, in reality, most contractors would operate their equipment more than 40 hours per week and more than five days per week, resulting in lower hourly rental rates.

For other cost estimates, the same rule should apply. For LOM cost estimates, use of the company's labour and equipment rates is a reasonable assumption for most closure activities, particularly earthworks, since by the time of closure, the operator should have excellent information on the actual costs incurred at the site. For activities, such as demolition and hazardous waste removal, local contractor rates may still be more applicable.

\subsubsection{The most suitable equipment for closure may not be the equipment at the site}

Because some of the equipment used at mine sites is often larger than the equipment a closure contractor would typically have available, assuming that the mine equipment fleet is appropriate for closure work may be inappropriate, and could lead to inaccurate closure cost estimates. The equipment used in the cost estimate may significantly impact the calculated productivity and total costs of closure. 
Another small working group comprised of Nevada mining industry representatives and regulators reviewed the types and sizes of equipment readily available from contractors and suppliers in Nevada, and limited the equipment choices for financial assurance cost estimates to that available equipment.

When preparing a LOM closure cost estimate, the on-site mobile equipment fleet should be reviewed with respect to its suitability for the planned closure activities. In many cases, there may be an auxiliary fleet used for construction that is more appropriate for closure activities than the primary mining fleet. For example, it may be more efficient and safer to haul cover materials to a tailings impoundment with smaller trucks than are used to haul ore and waste during mining even if this means obtaining the trucks from a local contractor or equipment dealer.

For ARO cost estimates, a similar approach to that used for financial assurance estimates may be appropriate since the financial reporting standards require that the cost be based on the assumption that a third party will perform the work. In this case, a review of equipment available from local contractors may be appropriate.

\subsubsection{The equipment productivities used should match the activity types}

There was a wide range of equipment productivities assumed in the cost estimates provided by various mining companies. Because the productivity of closure equipment fleets has a direct impact on the time required performing closure activities, it can have a profound impact on the overall closure cost estimate.

In Nevada, mining industry experts and the regulatory agencies determined that equipment productivities should be calculated based on accepted, published sources such as equipment manufacturers' handbooks, engineering manuals, and published construction cost databases to provide defensibility and consistency. In addition, typical correction factors were defined to ensure that the productivities represented an average range of conditions. This is believed to represent a conservative approach because the contractors typically used in the western US for closure work has highly experienced staff. In the case of highly specialised activities such as closure revegetation, fence removal or well abandonment, it was decided that local contractors could provide the best assessment of productivities by providing either the time or cost to perform an activity per unit dimension, i.e. area, length or volume.

For LOM cost estimates, the mining company may have a historical record of the key parameters affecting equipment fleet productivities including time for unplanned maintenance, fuel consumption rates, available equipment hours, high altitude performance and weather related factors. If so, these factors could be adjusted to reflect site specific conditions to provide a more realistic closure cost estimate for budgeting and planning purposes.

In the case of ARO estimates, use of standard productivities and average correction factors is a generally more acceptable approach. When audited, published productivities applied without generous correction factors tend to garner fewer concerns or questions.

\subsubsection{The cost and timing of process fluid management must be based on reasonable data}

The time required to stabilise a site for long-term passive management is directly related to the time needed to reduce the inventory of any remaining process fluids, install any long-term management systems, and ensure that the closure plan will limit the amount of water that must be managed in a passive management system. Estimating a short- and long-term water balance for a site requires a combination of science, engineering and professional experience. The industry has spent considerable effort globally in recent years to better understand this process for sites in closure. Most importantly, it is recognised that, although common approaches can be applied, each site is different and requires detailed analysis to define the parameters that will affect closure costs. Even then, most predictive water balance models require significant experience to use properly, and if used inappropriately or without a thorough understanding of the model and physics behind it, may result in unrealistic estimates. Whenever empirical data are available from a site, they should be used instead of or at least to calibrate any predictive model.

Recognising the site-specific nature of long-term fluid management plans, standard approaches and tools that use site-specific data have been defined by government agencies along with minimum design criteria and site data required to properly estimate the time and effort required to manage any solutions remaining on-site at closure. 
Costs associated with long-term water management are often the most difficult to predict, and can be substantial in current cost terms. However, since these costs are typically incurred very late in the project life cycle, and may extend beyond the closure period, they become less significant in the context of the net present value (NPV) of a project. For these reasons, many mining companies are accounting for long-term water management costs in LOM and ARO cost estimates by assuming a trust fund will be created at the beginning of the project and funded throughout the project. In this manner, a sustainable trust fund will be in place before the expenses are incurred. Using this approach moves the costs for financing the fund into the operational period and provides assurance that the funds will be available when needed.

\subsubsection{Additional permitting costs may be required prior to site closure}

None of the bankrupt sites in Nevada had included the cost of additional permitting or supporting closure studies in the financial assurance closure cost estimate. At a minimum, preparation of a closure plan, including collection of any required data, should be included. Additional permitting requirements may also include updated environmental impact analyses and detailed scientific studies to support the closure plan.

As closure was planned at each of the bankrupt sites, it became apparent that the financial assurance programme required revision to ensure that adequate funds were available to prepare a proper closure plan, including supporting studies. The federal land management agencies and the NDEP surveyed a number of consulting firms who prepared closure plans to determine the range of costs, and agreed to set typical closure planning costs based on the size and complexity of the mine. It was agreed that once a final closure plan was submitted and approved by the state and federal regulators, this cost could be removed from the financial assurance cost estimate.

The same principle should be applied to LOM and ARO cost estimates because closure planning and permitting costs are always a part of the closure process. Therefore, they should be included for budgeting purposes and defined for financial reporting.

\subsubsection{Include adequate costs for long-term site management and monitoring}

The requirements and period required for long-term site management and monitoring are highly site-specific. However, the same approach used to bring consistency to the calculation of process fluid management can be used to determine what, if any, long-term management and monitoring is required.

Site-specific studies and design requirements will determine the need and requirements for long-term site management and monitoring. Often, it is uncertainty that will dictate if or how much funding must be in place for long-term site management. In these cases, trust fund-type approaches are often used to ensure that there will be funding for both expected and unknown future site requirements. Monitoring requirements are typically based on the need to demonstrate stability at the site based on trends in empirical data. This will vary by site, but most regulatory agencies have guidelines for minimum requirements. Nevada's Water Pollution Control regulations allow the NDEP to require a 30 year monitoring period or longer if needed.

\subsubsection{Miscellaneous costs can add up}

The costs for removal of small infrastructure, e.g. power lines, substations, pipelines, etc., were not included or were underestimated at the abandoned sites in Nevada. Other miscellaneous costs, such as fence removal or installation, hazardous waste removal, construction or removal of erosion and sediment controls, were inconsistently addressed. In some instances, the total of these costs were substantial, especially where extensive linear infrastructure was part of the project.

Nevada mining industry personnel and the regulatory agencies cooperatively developed a checklist of miscellaneous costs that must now be considered for each site.

Depending on the specific requirements of the project, and the planned disposition of site and off-site infrastructure associated with the project, these costs may also be applicable for both LOM and ARO cost estimates. In some instances, some or the entire infrastructure may be owned by another entity or transferred to other entities at closure. In these cases, only the costs associated with transferring ownership should be included in a LOM cost estimate. However, if an asset is to be transferred at closure, then there must be documentation of this before closure of the asset can be removed from an ARO. 


\subsubsection{An accurate estimate of the cost to mobilise and demobilise from the sites must be included}

The cost to mobilise and demobilise (mob/demob) equipment, materials and labour to and from the sites was often excluded or inadequately estimated in the financial assurance cost estimates. These costs can be estimated as a percentage of the total closure based on experience, or more accurately by determining the number and types of equipment, materials and labour and calculating the actual number of trips and cost per trip. Although this cost primarily includes the direct costs to transport equipment and materials to the site, some contractors also include other costs such as office trailers, temporary power and other management costs in this line item.

After review, the industry and government agencies agreed that the cost to move equipment to and from a site being reclaimed should be added to the overall cost of reclamation. The specific items that should be included in the mob/demob cost were defined by a small working group, and local transport companies were contacted to determine the cost incurred to transport the necessary equipment to and from the site by a thirdparty transporter. Other common costs such as the establishment and use of office trailers, portable power and sanitary facilities were added to Nevada reclamation bonding guidelines as separate line items.

Because a LOM cost estimate may utilise equipment and labour already on-site, some of the mobilisation costs included in a financial assurance closure cost estimate may not be applicable to a LOM cost estimate. However, if third-party equipment will be used, mobilisation and demobilisation costs for that equipment should be included. Also, if the site is remote, the closure cost should include typical costs to house, feed and transport workers to and from the site during the closure period.

For ARO estimates, these costs should be included either as separate costs or included in the labour and equipment rates. For remote sites, actual site data for accommodation costs are usually acceptable.

\subsubsection{Unit rates should be current}

Although Nevada's regulations require that bond costs are updated every three years, the hourly rates often change annually based on current economic conditions. Although most annual variations are generally small, financial assurance and closure cost estimates should be based on current rates.

NDEP and federal regulatory agencies update equipment, labour and material rates each year and post the current rates on a public web site for use in reclamation bond cost estimates.

In some jurisdictions, the term of the permit also defines the period for closure cost updates. Where these terms are longer than one or two years, an escalation factor is applied to ensure the financial assurance will remain current with current economic conditions throughout the term of the cost estimate.

Because LOM cost estimates are typically updated based on the site budgeting cycle, and ARO costs must be updated every year, the basic unit rates for equipment, labour and materials should be updated each time the closure cost is updated. Once a closure cost estimate model is built, updating the unit rates can be one of the most time consuming parts of the update process.

\section{$4 \quad$ The influence of financial reporting on closure cost estimates}

While the laws of the 1970s, 1980s and 1990s created the need for closure cost methodologies, and the failure of a number of mines around the turn of the millennium caused the industry and government regulators in many countries to make significant revision to financial assurance programmes, it has been the need for more accurate financial reporting following the failures of Enron, Tyco and other major public companies in the early 2000s that has been the catalyst of the most significant changes in closure cost estimating philosophy and methodologies in the last 10 years.

Although the financial reporting requirements documented in the Financial Accounting Standards (FAS) Statement 143 and IAS Standard 37 have been in existence since 1998, it was the realisation following the Enron scandal that incomplete or poorly defined closure liabilities could result in inaccurate financial reporting, that many mining companies and financial auditors began to seriously rethink their philosophy toward the preparation of closure cost estimates. In addition, the new Canadian requirements for public disclosure that resulted from the Bre-X scandal of 1997 placed increased pressure on the authors of prefeasibility and feasibility studies to ensure that all liabilities are properly documented. 
As a result of these collective reflections, the closure plans for many sites came under increased scrutiny by corporate management along with the cost estimates based on those plans. Mining companies began to implement detailed reviews of existing plans and found that many were poorly defined and had not been reviewed regularly since they were originally written. In particular, plans for projects with long life cycles were often discounted as being relatively unimportant due to the long time before any closure would occur. Mines located in jurisdictions that required detailed financial assurance cost estimates or those owned by companies with strong environmental programmes were often found to be adequate, but many would not pass the scrutiny of an ARO audit needed for financial reporting or stock market listing. Some of the common deficiencies were similar to those found in the bankrupt properties in Nevada, but most importantly, many of the early closure cost estimates did not contain sufficient detail or backup documentation to support a rigorous financial audit.

Internal and external financial auditors must be able to confirm that an ARO cost estimate is based on the best available data and represents a realistic cost to close the site. Therefore, all ARO cost estimates must be based on site-specific data to the degree possible, and supported with detailed calculations as to how much work will be done, how long it will take, and what resources will be required. Other approaches, such as documented costs for contemporaneous closure activities may be submitted as support for the cost estimate, but generally methods such as cost-per-area estimates are not acceptable unless proper documentation is provided to demonstrate the applicability of those costs to the site in question.

Another important difference between financial assurance cost estimates and AROs is that AROs are estimated on a cash flow basis. This requires the estimator to evaluate not only the activities required for closure but the timing of each. Preparing a cash flow schedule of closure liabilities requires not only a clear understanding of how each facility will be decommissioned and closed, but also when each activity will occur and how that facility will be closed in the context of the overall closure schedule.

The public scandal surrounding the Bre- $X$ failure resulted in the promulgation of the Canadian Securities Administrators' National Instrument 43-101 (NI 43-101) in 2001. The NI 43-101 rules implemented new requirements for the public disclosure of information relating to mineral properties. Although primarily focused on the disclosure of mineral resources and reserves, the NI 43-101 and the comparable Australian Joint Ore Reserves Committee Code (JORC Code) have also resulted in increased scrutiny in the calculation of all assets and liabilities associated with mineral properties documented in reports such as prefeasibility and feasibility studies. As a result, closure cost estimates included in NI 43-101 compliant reports are now prepared in greater detail than previously and are often similar in detail to ARO cost estimates.

The influence of the new requirements and awareness of financial reporting requirements has resulted in the next evolution of mine cost estimating standards and methods. Building on the increased level of detail in closure plans resulting from financial assurance programme restructuring in the early 2000 s the industry has increased the detail, quality and in most cases the quantum of estimated closure costs used for budgeting and financial reporting purposes. Because each company is required to prepare closure cost estimates for three separate purposes, each with slightly different requirements, companies are developing new cost estimating tools or modifying existing ones to simplify the process of preparing and maintaining closure cost estimates for multiple purposes.

One example is Barrick Gold's use of a modified version the Nevada SRCE. In Barrick's version of the model, known as the Barrick reclamation cost estimator (BRCE), all three types of closure cost estimates use the same basic site information, but utilise different equipment, labour and material cost databases to estimate each type of estimate from the same site information. Additional features added to the BRCE include additional closure activities, cost scheduling and automated routines to determine which costs should be included in the different cost estimates based construction and closure dates, and the type of expenditure. This model is now being used by Barrick at most of their operations for budgeting and planning, ARO cost estimates, and in Nevada for financial assurance cost estimates. It is also proving to be a valuable tool in the evaluation of new capital projects.

\section{$5 \quad$ Future trends in mine closure cost estimates}

Even with improvements made over the past two decades in closure cost programmes for FACE, LOM and ARO cost estimates, and the development of more accurate and sophisticated estimating tools, the residual 
risks associated with closure cost estimates are likely to lead many companies (and possibly government agencies) to conduct regular formal assessments of the mine closure objectives and assumptions for many operations to ensure that the cost estimates are indeed accurate. In some cases, the results of these formal risk assessments (FRA) may indicate the need for additional studies to determine if the closure plan objectives can realistically be achieved and/or what, if any, additional costs may be incurred to achieve the objectives of the closure plan.

With the publication of the equator principles and international finance corporation (IFC) stakeholder consultation standards, the involvement of public stakeholders and surrounding communities in the development of mine closure objectives and financial assurance requirements has increased considerably in the last decade. This has resulted in the examination and incorporation of stakeholder input into closure planning earlier in the mine life cycle through proactive stakeholder engagement, and consideration of the stakeholder programmes in the preparation of FACE, LOM and ARO cost estimates.

It is currently unclear how new climate change thinking may affect long-term closure design criteria, for example, the consideration of frequency and magnitude of severe storm events used to determine closure designs. The requirements of modelling post-closure conditions may also change to reflect uncertainty in long-term climate conditions. These changes may result additional costs associated with site closure planning, closure construction, water treatment, and long-term monitoring and maintenance.

\section{Conclusions}

The combination of continual improvements in financial assurance standards and the new focus on financial reporting has resulted in a number of changes in the methods and standards used by the mining industry to estimate closure costs. Whereas, in the early 1990s it was common to find that closure cost estimates used for financial assurance purposes were significantly less than those used for internal budgeting and reporting purposes. Because of the hard lessons learned by the mining company failures in the early 2000 s closure plans are more comprehensive and detailed, and the variance between the different types of cost estimates has narrowed significantly with the variances primarily due to the different purposes of the estimates. Today the financial assurance estimate is often the highest estimate of the short-term liabilities because of special government guidelines and the indirect costs, which can add as much as $40-60 \%$ to the direct costs.

The emphasis on estimating the quantum of financial assurance necessary to comply with government regulations compelled the mining industry and government agencies to develop and standardise methods to estimate closure liabilities since the mid 1970s. Although the implementation of new laws and revision of existing laws in many countries will continue to impact the methods and standards used to estimate closure costs for the foreseeable future, the need to accurately report closure liabilities in compliance with financial reporting regulations has become the primary force in advancing the technology of cost estimating. Now that the issue of closure cost estimates has made it to the corporate boardroom, the availability of resources and need to standardise estimating methods is likely to push closure cost estimating technology forward faster than any time in the past 30 years.

\section{Acknowledgements}

The authors would like to thank Barrick Gold Corporation for their support in the ongoing development of the standardised reclamation cost estimator for public domain use. Specifically, we would like to acknowledge Ron Espell, Joseph Giraudo, Jim Alto and Cliff Rodgers.

The authors would also like to acknowledge the contributions of the Northwest Mining Association and in particular Laura Skaer and Debra Struhsacker for their efforts to ensure that accurate information on hard rock mining issues are available to the public and the elected government of the US and other countries.

\section{References}

International Accounting Standards Board (IASB) (2004) Notes from IASB Board Meeting 18-19 May 2004, London, p. 5 .

Miller, C.G. (2005) Financial Assurance for Mine Closure and Reclamation: A study prepared for the International Council on Mining and Metals (ICMM), London, p. 67. 
New South Wales Department of Primary Industries (NSW-DPI) (2005), Mineral Resources EDP11 Rehabilitation security deposits policy, 1 p., viewed 20 June 2009, http://www.dpi.nsw.gov.au/__data/assets/pdf_file/0020/96104/EDP11-Rehabilitation-security-policy-200511.pdf

New South Wales, Department of Primary Industries (NSW-DPI) (2006), Mineral Resources Division, ESB20, Rehabilitation Security Deposit Requirements for Mining and Petroleum Titles, 17 p., viewed 20 June 2009, http://www.dpi.nsw.gov.au/_data/assets/pdf_file/0020/96131/esb20-Rehabilitation-Security-DepositRequirements-for-Mining-and-Petroleum-Titles.pdf.

Parshley, J.V. and Struhsacker D.W. (2009), The Evolution of Federal and Nevada State Reclamation Bonding Requirements For Hardrock Exploration And Mining Projects: A Case History Documenting How Federal and State Regulators Used Existing Regulatory Authorities to Respond to Shortcomings in the Reclamation Bonding Program, Northwest Mining Association, 7 p, viewed 25 June 2009,

http://www.nwma.org/pdf/NWMA\%20reclamation\%20bonding\%20white\%20paperHR\%20699.pdf. 